\title{
Journalism as Potential Approach for Climate Change
}

\author{
Taksina C. ittipornwong
}

\begin{abstract}
The study aims to enhance a practice of VIEW communication as journalism approach for fostering climate change adaptation. A composition of VIEW communication is described by four approaches taken by journalists and news reporters. They are V-verification, I-information, E-education and $\mathrm{W}$-warning. The research design is based on a cross-section analysis of news content reported through TV media about weather conditions, climate situation and natural crisis during raining season in year 2011 and 2017 in Thailand. The questions are as to how the journalists account for climate agenda, especially adaptive capacity, what differences in terms of VIEW communication behind the cross-sectional cases, which approach is best taken and how it is, and what is the ultimate outcome in relation to climate agenda, with emphasis on climate change adaptation. The representatives from professionals and academia in journalism, in environment and climate sciences, and TV news audiences were responsible for the test, with three-point scales varying from the levels of truly engaged, moderately, and never. The prominent findings are that VIEW communication is truly engaged for climate news reporting, and that the task in 2017 is much more common to VIEW communication, with truly-engaged level, than those in 2011 consistent to moderate level. E approach for the 2017-case is justified at moderate level by the environment and climate experts, while the results towards 2011-case sound different. They least engaged in $E$ approach whereas $I$ and $W$ rise to truly-engaged level. The informants also agree that TV news audiences are received several signs of alert and aware to damage prevention and risk reduction whereas journalists are likely to have information verified with the experts in the field. News reporting, with audio-visual feature, through the VIEW communication is best for building adaptive capacity on climate change environmental consciousness and turning public awareness into behavioral participation.
\end{abstract}

Index Terms-Climate change adaptation, environmental journalist, journalism, news reporting.

\section{INTRODUCTION}

The world has been addressing more particular concern to unsustainable use of natural resources, regardless of resource efficiency, greenhouse-gas emission reduction, and adverse impacts on human security, presently and next generation. Human generally behaves to satisfy the opportunity to consume and the sense of fulfillment [1]. A daily lifestyle can cause environmental harms and puts the planet away from sustainability. In other words, climate change is primarily resulted by our choices and behaviors. As climate impacts on

Manuscript received July 30, 2017; revised September 28, 2017. This work was supported in part by the Department of Research and Development, Muban Chombeung Rajabhat University.

T. C-ittipornwong is with Muban Chombeung Rajabhat University, Ratchburi, PO 70150 Thailand (e-mail: natcna@gmail.com). almost everything human do for life, environmental coexistence that refers to a sustainable relationship between society and nature for a reduction of vulnerability to environment and nature needs to be taken and practically deployed to all concerns [2]. One way for this expectation is to enhance a profession of journalism where is behind an environmental communication.

Journalists as media professionals are able to address public interest in climate issues through news content and presentation format. In general, news consumption is best for satisfying human need to be inside the mainstream behavior. It also represents as to how people alternate their uses and gratifications to news story. As such, the way of news production and consumption can be a crucial ingredient of environmental consciousness development and a strategic tool for rising climate mitigation and adaptation actions [3].

Due to popularity of the Internet that makes many voices one world [4] and several advances in communication technology, newspaper is no longer a source of daily news. Internet news has become as an entirely new forum of communication between news sources and individuals. Online media is redefining the way the media operates and breaking down the typical practices in news production and consumption [5]. Eventually, journalists are forced to make a transition to online news as people want to have a fast and easier access to information about social movement. In addition, audio-visual media, either on a track of TV broadcasting or online media is great for photojournalism on the coverage of natural environment and climate stories. News in audio-visual format or video feature can deliver a greater presentation of news story with motion pictures and sound effects. Last but not least, as journalism can be a strategic device for tackling climate problems, then what actions the viewers and media professionals had to take in relations to the nature and environment and what have been the main challenges along the way. Actually, how has society benefited from the efforts to manage climate agenda?

\section{Theoretical base Related to Research Hypotheses}

\section{A. Journalism}

The profession of writing for newspapers is determined for journalism that has journalist gather and report the news plays in our lives. News not only allows journalists to listen to what people all over the world are saying about a particular subject, but also reports live on an event. Not just the facts journalists find for public, but it is the truth about the facts [6]. Due to the career, the journalists gain exclusive insights into the story by possibly accessing sources of information, even key players 
behind the situation. They can provide different perspectives on the coverage and challenges in which the concerns get experienced. The purpose of journalism is therefore to provide people with the verified information potential for better decision about their lives and societies. It also signifies public movement and stands for the voice of society [7].

Journalism can promote and enhance all efforts of citizen and government by setting them as social agenda, bridging the roles of all concerns as well as building an updated information sharing system. As natural crisis is the world agenda that causes the damage to all lives, it is challengeable for the journalists in reporting news of climate and natural crisis quickly, timely, and accurately. The considerations include how to write or produce effectively so as to generate public debate and action linking to influencing decision necessary for driving the process, and what is the context and with what it connects [8].

These have journalists engage their performances of news production and presentation, with emphasis on the VIEW communication, which is a systematic process. The compositions are verification- $V$, information-I, education- $E$, and warning- $W$. The following diagram illustrates what are determined for every approach of the VIEW communication.

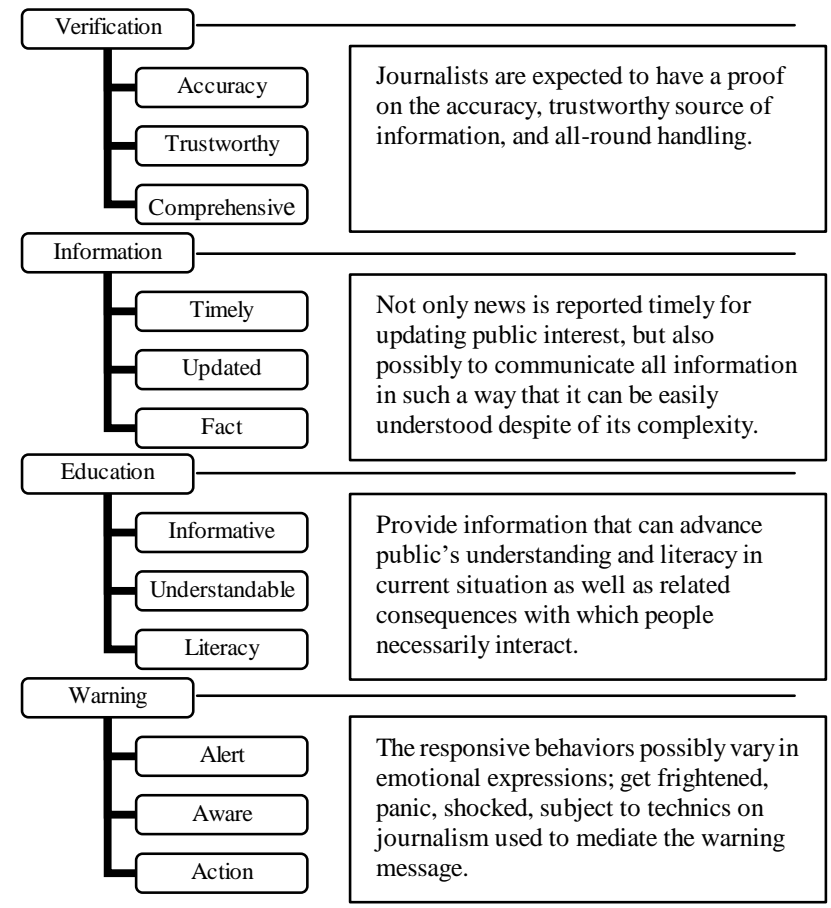

Fig. 1. Indexes behind a success of every approach to VIEW communication.

An approach of verification requires journalist's attempt to verify accuracy and trust of information sources together with signifying news value around before distribution.

Following information approach, as time is frozen for news reporting, journalists have function to tell facts of event timely and updated. News reporters are also focused on presenting the facts that needs academic information and advices from either the experts or the person experiencing the real event.

Due to education base, climate change is a complex issue to navigate and understand scientific issues better. It is possibly difficult for journalists to write an environment or climate report, however it is necessary to make the writings understandable. In particular, news production and consumption can alternate social development. It means journalists are perfect to educate people on what they can do to improve their environment which also means improving their way of life and ensuring a better future for themselves and the world. If the truth is continuously pursued and reported, people are well-informed and explained causes and effects following situation changes.

The last one as warning refers to news content and presentation that make audiences alert, aware and active to handle the consequences in terms of prevention, protection and risk reduction. The interesting is news can develop audience's gratification that varies from the expressions of adaptation to the circumstance, shaping life to existing environment, and far to a selection of new environment [9].

\section{B. News Reporting}

News contents are marked by a simplicity and directness of expression of a factual story that is associated with public interest. A research on the Thai viewer's gratification to news consumption via TV media reveals that climate and environment news is hardly viewed whereas gender is an influencing factor [11]. The finding also showed that life and entertainment news was on the contrary, but most potential to viewer's gratification development. One more interesting thing mentioned in the Reporter's Environmental Handbook is that environmental journalists perceive the stories of water resource as the most important environmental issue, followed by atmospheric air pollution concerns, endocrine disruptors, and waste management [12]. Environmental journalists are likely to report locally-environmental issues, rather than global concerns [13].

In digital age, communication tools are everywhere so everyone can transmit information across channels, with a fast and convenient pace. News can flow to the receivers at any time, through several channels, and by their own decision in which they keep interested, including sharing and comment distribution. Among Thais, the consumption of audio-visual news broadcasted through TV media, even smart media are largely increasing. TV program production has photographs, illustrations, and info-graphics used for presenting news about weather conditions, climate situation, and natural crisis. Technic of news reporting via audio-visual media is best designed with two major factors; content and presentation. These are aligned with the VIEW communication and bring about successful path to new journalism and environmental journalists.

\section{Climate Adaptation}

The International Panel on Climate Change (IPCC) addressed that climate adaptation is as the ability of natural or human systems to response to actual or potential damage and cope with the consequences. In other words, adaptation to climate change refers to an understanding of how individuals, groups and natural systems can prepare for and respond to changes in climate and their environment [14]. Due to increase 
of natural crisis globally, a development of adaptive capacity have been addressed to all nations. Successful adaptation by individuals and communities is a crucial factor for vulnerability reduction. The devices are as alternating any possibility and strengthening every strategy and tool those effective to a reduction of negative impact together with a maximum benefits from changes in climate.

The terms adaptation is actually aligned with mitigation terms which is the other fundamental condition in the climate change debate. Mitigation is to tackle the causes of climate change whereas adaptation tackles the effects by finding way to live with the consequences of global warming. The greater the degree of adaptive capacity is, the less the degree of climate impacts is deployed to our lives. Sustainable development and diversification are still important strategies wherever possible. These bring many challenges for people and government in reaching climate adaptive capacity. The efficiency comes true if the collective action is internally driven, not externally imposed. Likewise, the journalists will realize that mass media can generate public awareness to protect, preserve and conserve the planet from the climate crisis. Eventually, the environmental journalists can use either news processes or media products to capture climate adaptation agenda, raise environmental consciousness, and enhance public participation in turning relevant thoughts and policies into implementation.

\section{Environmental Journalists}

Actually, journalists are likely to report the subjects of current affairs, politics, economy, sports, entertainment, terrorism, and international relations those covering the areas of violence, sex, offences and crimes, and privacy. The reporters chose presenting the fact of death happened to those who sacrifice to conserving and protecting their local resources and habitats. Truth behind the fact regarding why and what related to environmental protection after the death of victims are hardly accomplished. The possible explanation is that environmental stories are complex and difficult to report [15]. If lacking of knowledge about environment and natural sciences, the works might be less satisfactory for audiences. Additional are a limited access to environmental data provided by the governmental agencies, a need in much more time and attempt for writing when compared to general subjects, and a threat to their professional activities as well as their private lives. Also, dialogues and deliberation on environmental issues cover a large scope of news are not getting enough interest from news editorials, sponsors and consumers.

Journalists can share the responsibility to planet improvement. Their power in using the media for social agenda setting is evident. The Guardian; one of the top-read newspaper in United Kingdom, succeeded in setting the crowd source to investigate the accountability of government and political officers like Mr. Gordon Brown's, ex-PM of England, under the project of MP Expense Scandal [15]. National Geography produces a lot of photo-essays and news stories covering flora and fauna resources and their endangered species. These features are contributed in the magazine as well as broadcasted on TV media, including other audio-visual outlets, globally. The tasks are at least able to educate people about the degradation of natural resources and the climate consequences, and promote environmental consciousness of resource sufficiency and impact reduction. To complete these works, it is necessary for the authors and the producers to get the sufficient understanding of ecosystems, the extinction of threatened animals and endangered plants, deforestation, soil and water management. Behind the journalism philosophy, news reporters can play the role in shaping people's understandings of themselves to climate issues.

\section{Methodology}

\section{A. Scopes of Study}

The research was based on the cross-sectional method. News about Thailand climate and weather conditions that cause heavy rain, flash floods, and storms were used as study cases. The study focused on the specific news produced in an audio-visual format and mediated against two periods. They were a second-half 2011 and a first-half 2017 addressed as Disaster 1 (D1) and Disaster 2 (D2), respectively.

D1 covers the biggest news of severe flooding spreading over the country particularly in the outskirts of Bangkok in 2011 from July to next January. This situation was described as the worst flooding due to the amount of water, and 13.6 million people affected, with a total of 815 deaths. D2 refers to heavy rainfalls and flooding causing a variety of damages, even death, to hundreds of thousand lives in all parts of country since December 2016 to May 2017.

News series of D1 and D2 derived from free-TV media where included the channels of MCOT, Thai PBS, TV 3, TV 7 and Nation TV. The approaches of VIEW communication were used as the indicators to examine the hypotheses on potentiality of journalism for climate adaptation among the Thais. The informants were 30 samples by ten at each derived from media professionals, experts in environment and natural science, and audiences.

\section{B. Procedure}

Behind the study on VIEW criteria, the distinct questions were (1) which approach was best taken, (2) how to engage, (3) what were differences between two news series and (4) how developed, and (5) a potential of journalism as a tool for building public adaptation for climate crisis. The informants were asked to view the series of D1 and D2 news, with consideration on the journalism engaged in the news touching their heart. They gave answers based on a three-point scale. The levels were scaled from truly engaged, moderately, and less to the least. Except for the audiences group, each representative received video copies of D1 and D2 news series for viewing at home. For the audiences, the control-conditions of place and time are arranged for approximately one hour. They together viewed the news series those played continuously before handling the choices of questions. 


\section{RESULTS and DISCUSSION}

\section{A. Overview}

As the data in Table I, most journalists are truly engaged in reporting climate news, with the mean 2.40. This is concurrent to the appraisal results from media professional, and audience representatives, with the mean value 2.40 and 2.49 , respectively, whereas the experts in natural environment and climate think differently as pointing at moderate level. All groups have the same conclusion that news of D2 refers to climate situation during the $1^{\text {st }}$ half 2017 is more common to VIEW communication than D1 news those covering the period of $2^{\text {nd }}$ half 2011. It is apparent that journalists have lessons learned about climate news reporting as they shift up to a truly-engaged level after the moderate performances in 2011. As news can be portrayed with photographic and info-graphic technologies for better presentation, especially through audio-visual media, a concept of VIEW communication is possibly applied for reporting climate news.

TABLE 1: A VIEW COMMUNICATION OF JOURNALISM FOR CLIMATE NEWS

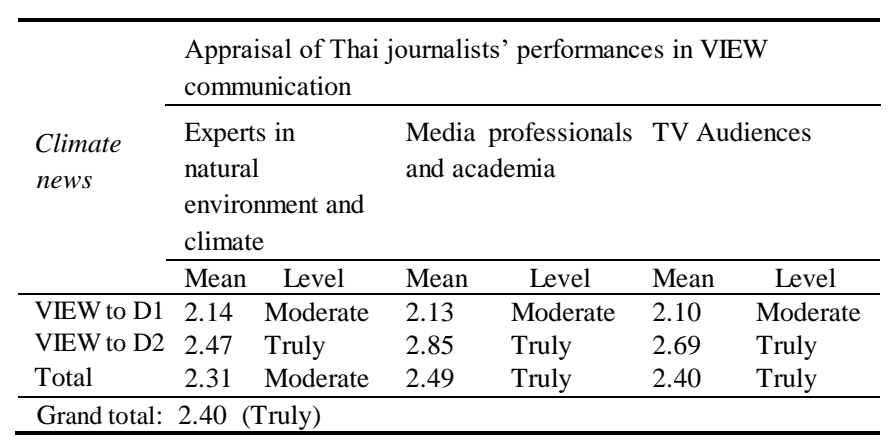

TABLE II: JOURnALISTS' PERFORMANCES AGAINST Climate NEWS IN 2011

\begin{tabular}{|c|c|c|c|c|c|c|}
\hline \multirow{3}{*}{$\begin{array}{l}\text { Disaster } 1 \\
\text { Climate } \\
\text { situation } \\
\text { in } 2^{\text {nd }} \text { half } \\
2011\end{array}$} & \multicolumn{6}{|c|}{$\begin{array}{l}\text { Appraisal of Thai journalists' performances in VIEW } \\
\text { communication }\end{array}$} \\
\hline & \multicolumn{2}{|c|}{$\begin{array}{l}\text { Experts in } \\
\text { natural } \\
\text { environment and } \\
\text { climate }\end{array}$} & \multicolumn{2}{|c|}{$\begin{array}{l}\text { Media professionals } \\
\text { and academia }\end{array}$} & \multicolumn{2}{|c|}{ TV Audiences } \\
\hline & Mean & Level & Mean & Level & Mean & Level \\
\hline Verification & 1.87 & Moderate & 2.22 & Moderate & 2.22 & Moderate \\
\hline Information & 2.63 & Truly & 2.30 & Moderate & 2.22 & Moderate \\
\hline Education & 1.99 & Moderate & 1.58 & Least & 2.07 & Moderate \\
\hline Warning & 2.07 & Moderate & 2.40 & Truly & 1.87 & Moderate \\
\hline VIEW & 2.14 & Moderate & 2.13 & Moderate & 2.10 & Moderate \\
\hline
\end{tabular}

TABLE III: JOURNALISTS' PeRfoRmanCES AgAinst Climate NEWS IN 2017

\begin{tabular}{|c|c|c|c|c|c|c|}
\hline \multirow{3}{*}{$\begin{array}{l}\text { Disaster } 2 \\
\text { Climate } \\
\text { situation } \\
\text { in } 1^{\text {st }} \text { half } \\
2017\end{array}$} & \multicolumn{6}{|c|}{$\begin{array}{l}\text { Appraisal of Thai journalists' performances in VIEW } \\
\text { communication }\end{array}$} \\
\hline & \multicolumn{2}{|c|}{$\begin{array}{l}\text { Experts in } \\
\text { natural } \\
\text { environment and } \\
\text { climate }\end{array}$} & \multicolumn{2}{|c|}{$\begin{array}{l}\text { Media professionals } \\
\text { and academia }\end{array}$} & \multicolumn{2}{|c|}{ TV Audiences } \\
\hline & Mean & Level & Mean & Level & Mean & Level \\
\hline Verification & 2.39 & Truly & 2.92 & Truly & 2.87 & Truly \\
\hline Information & 2.84 & Truly & 2.88 & Truly & 2.44 & Truly \\
\hline Education & 2.22 & Moderate & 2.58 & Truly & 2.46 & Truly \\
\hline Warning & 2.42 & Truly & 3.00 & Truly & 3.00 & Truly \\
\hline VIEW & 2.47 & Truly & 2.85 & Truly & 2.69 & Truly \\
\hline
\end{tabular}

\section{B. Comparative Assumptions}

The first scenario that assigned for climate news in 2011 as displayed in Table II show that just only two in twelve answers gathered from all groups associate with truly-engaged level. One is for an I-information given by the experts in environment and climate issues. The other determined by media representatives is deployed for $W$-warning indicator. The prominent significance found in this study is the level of least engagement that the media assess themselves, with the mean 1.58. In the audiences' opinion, journalists are moderate to all approaches in handling VIEW communication.

Comparing to the results found for the second scenario as D2 news drawn in Table II, everything has great change. All indexes show the best contribution by which news do for them, except for the E-education criteria, just on moderate level in view of environmentalists and their colleagues. These interpret that the journalists who have been working on the coverage of climate and weather issues are getting a closer look at the climate agenda. The more the climate change impacts on lives, the more the fact behind the news story need to be discovered to the public. The approach of VIEW communication behind journalism-based philosophy can be a driving force to building mitigation and adaptation behaviors that relates to the collective action internally driven, not just externally imposed.

\section{Conclusion}

The approaches for deploying a VIEW communication to climate issues have been truly developed for TV news reporting in Thai context. Among the journalists, there exists a growing concern to perform a VIEW communication for climate news as the result of news reporting about climate situation in $1^{\text {st }}$ half 2017 is determined at truly-engaged level, while the prior case in 2011 is equal to moderate level. Warning approach is best taken, with emphasis on having people either alert to, or aware of risk prevention and reduction. Due to the complexity of climate and environment sciences, journalists are likely to take a verification of information accuracy with the experts and academia in the field prior reporting to the public. The verification approach helps them to literally and professionally do things on climate issues as the role of journalists who report interesting and significant facts to the public. Today, the journalists are challenging themselves in producing climate news, with a growing concern to scientific knowledge and raising public awareness of climate change adaptation. Most journalists realize that news production and presentation can generate public consciousness to protect, preserve and conserve the planet from the climate impacts those largely addressed as the world agenda. A VIEW communication behind journalism on climate issues can provide key insights for identifying human capacity on climate adaptation. Eventually, the environmental journalists can use news processes and media products to raise environmental consciousness, enhance actionable public participation and environmentally community-based project implementation for achieving sustainability and the SDGs. 


\section{REFERENCES}

[1] W. Zhao and P. Schroeder, "Sustainable consumption and production: trends, challenges, and options for the Asia-Pacific region," Natural Resources Forum, pp. 4-15, 2010.

[2] S. Maesinsee, "The Future of global system \& the quest for the new science discipline," presented at A Technology Foresight Symposium, Bangkok, February 23, 2010

[3] S. Kaviya, Earth Journalism, 1st ed. Bangkok, Thailand: Kosintre Book House, 2006, ch. 3, pp. 61-89.

[4] S. MacBride, Many Voice, One world: Towards a New, More Just, and More Efficient World Information and Communication Order, London, UK: London Kogan Page, 1983.

[5] J. K. Lee, "The effect of the internet on the media agenda," Journalism and Mass Communication, vol. 4, pp. 745-760, Quaterly, 2007.

[6] B. Kovach and T. Rosenstiel, The Elements of Journalism, New York, USA: Crown Publishers, 2007.

[7] S. Kaviya, Applied Communication Theories (ACT), 1st ed. Bangkok, Thailand: Kosintre Book House, 2011, ch. 1, pp. 9-21.

[8] S. Kaviya, Earth Journalism, 1st ed. Bangkok, Thailand: Kosintre Book House, 2006, ch. 5, pp, 109-123.

[9] W. Samkoses, Live \& Learn: Edutainment Essay, Bangkok, Thailand: Openbooks, 2011, ch. 1, pp. 8-13.

[10] C. H. Lee, The Role of Wisdom, Singapore: Nanyang Technology University, 2009.

[11] T. C-ittipornwong, "The undercurrents of media convergence and development of viewer's gratification to news consumption," MediAsia 2015 Conference Proceedings, 2015, pp. 5-15.
[12] C. Vadhanaputi, J. Bird, and J. Dore, "Regionalization of development: Challenges for research-policy platforms," presented at the Dialogue Forum on Social Policies in Southeast Asia: Probing the Social Science Policy Nexus, Bangkok, Thailand, August 20-22, 2008.

[13] A. Anderson, Media, Culture and the Environment, USA: Taylor and Francis, 1997.

[14] K. Peattie, "Green consumption: Behavior and norms," Annual Review of Environment and Resource, pp. 195-228, vol. 35, 2010.

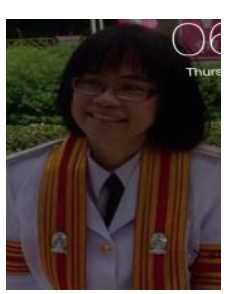

Taksina C-ittipornwong is currently a principle lecturer and the head to the Communication Arts Division in Muban Chombeung Rajabhat University, Ratchburi province where is in the western part of Thailand. She also has been the host to academic radio program broadcasted via Radio Thailand since 2007.

She has two master degrees; Journalism and Mass Communication from Thammasat University as well as Forestry Science from Kasetsart University, and holds the Ph.D. in Environment, Development and Sustainability from Chulalongkorn University. She has spent more than 35 years working in two major areas where her career successes were substantial. A half period of her working life was first devoted to the top-ranked company of petroleum and petrochemical businesses, with the retirement position of assistant vice president. For the progress in media field, she is a former director of the Executive Board for Thai Public Broadcasting Service (Thai PBS), and still continues the interest to integrate her knowledge and experiences into teaching and research works as head of Communication Arts Division in Muban Chombeung Rajabhat University. 